\title{
Risk factors associated with injection initiation among drug users in
} Northern Thailand

\author{
Yingkai Cheng 3 , Susan G Sherman ${ }^{3}$, Namtip Srirat ${ }^{3}$, Tasanai Vongchak ${ }^{3}$, \\ Surinda Kawichai ${ }^{3}$, Jaroon Jittiwutikarn ${ }^{3}$, Vinai Suriyanon ${ }^{3}$, \\ Myat Htoo Razak ${ }^{3}$, Teerada Sripaipan ${ }^{3}$ and David D Celentano*1,2,3
}

\author{
Address: ${ }^{1}$ Johns Hopkins University, Bloomberg School of Public Health, Baltimore, MD, USA, ${ }^{2}$ Research Institute for Health Sciences, Chiang Mai \\ University, Chiang Mai, Thailand and ${ }^{3}$ Ministry of Public Health, Nonthaburi, Thailand; Family Health International, Bangkok, Thailand \\ Email: Yingkai Cheng - ycheng@jhsph.edu; Susan G Sherman - ssherman@jhsph.edu; Namtip Srirat - rhonsrrk@chiangmai.ac.th; \\ Tasanai Vongchak - tvongcha@chiangmai.ac.th; Surinda Kawichai - surinda@loxinfo.co.th; Jaroon Jittiwutikarn - jjaroon@loxinfo.co.th; \\ Vinai Suriyanon - mhrazak@fhibkk.org; Myat Htoo Razak - rihesvac@loxinfo.co.th; Teerada Sripaipan - tsripaip@jhsph.edu; \\ David D Celentano* - dcelenta@jhsph.edu \\ * Corresponding author
}

Published: 14 March 2006

Harm Reduction Journal2006, 3:10 doi:10.1186/1477-7517-3-10
Received: 04 November 2005

Accepted: 14 March 2006

This article is available from: http://www.harmreductionjournal.com/content/3/1/10

(c) 2006Cheng et al; licensee BioMed Central Ltd.

This is an Open Access article distributed under the terms of the Creative Commons Attribution License (http://creativecommons.org/licenses/by/2.0), which permits unrestricted use, distribution, and reproduction in any medium, provided the original work is properly cited.

\begin{abstract}
Background: Circumstances surrounding injection initiation have not been well addressed in many developing country contexts. This study aimed to identify demographic factors, sexual behaviors and drug use characteristics related to injection initiation among drug users in northern Thailand.

Methods: A cross-sectional survey was conducted among 2,23I drug users admitted to the Northern Drug Treatment Center in Mae Rim, Chiang Mai, Thailand, between February I, 1999 and December 3I, 2000. A multiple logistic regression was employed to identify the independent effects from potential risk factors of transition into injection.

Results: After controlling for other covariates, being 20 years of age or older, single, ever receiving education, urban residence, and having a history of smoking or incarceration were significantly associated with higher likelihood of injection initiation. Multiple sex partners and an experience of sex abuse were associated with an increased risk of injection initiation. Comparing to those whose first drug was opium, individuals using heroin as their initiation drug had greater risk of injection initiation; conversely, those taking amphetamine as their first drug had less risk of injection initiation. Age of drug initiation was negatively associated with the risk of injection initiation: the older the age of drug initiation, the less the risk of injection initiation.

Conclusion: Injection initiation was related to several demographic factors, sexual behaviors and drug use characteristics. Understanding these factors will benefit the design of approaches to successfully prevent or delay transition into injection.
\end{abstract}

\section{Background}

A range of studies have examined the factors associated with transition from non-injection into injection drug use; however most of them are conducted in the devel- 
oped world [1-5]. This transition is a critical point in a drug user's career for many reasons, particularly because it is characterized by a heightened risk of acquiring HIV and other blood-borne pathogens [6-8]. The process of initiating injection is complicated and informed by a myriad of individual, social-culture, and environmental factors. Demographic characteristics significantly associated with transition into injection in developed countries have included: being of younger age [5,9]; being female [10]; ethnic minority $[3,11]$; housing instability [5]; and being a high school dropout [3]. Having a current steady sexual relationship with a partner who is an IDU has long been observed as a facilitating factor for transition into drug injection [12]. Sexual abuse alone has put drug users at a higher likelihood of injection initiation $[5,13]$. Many studies have recorded the independent effect of drug use characteristics on onset of injection, such as types of recently used drugs [5,12]; intensiveness and/or length of drug use [9-12,14,15]; and current treatment status [1]. At the social-culture level, low socio-economic status has consistently been found to be one of the most important factors in initiating injection in the developed world $[2,4]$.

An exploration of the circumstances around the critical time of initiating injection practices in developing countries as related to medical outcomes has not been well addressed. Limited evidence from China $[16,17]$ indicated that risk factors of injection initiation in developing countries could be as similar as those in developed countries like younger age, ethnic minority and short duration of heroin use. However, Lai et al [17] reported that being male related to higher risk of injection initiation, which has not been shown in other studies $[10,18]$. The situation in Thailand is of particular interest because injecting drug use continues to be a leading risk factor for HIV in the country that was previously characterized as having a heterosexual epidemic [19]. After implementing the $100 \%$ condom use program in the 1990s, by 2002 the national HIV prevalence was about $2 \%$ and prevalence among 21 year-old military conscripts was under 1\%, having dropped from $4 \%$ in the mid-1990s [20]. Unfortunately, similar prevention efforts have not been waged to reduce HIV infection among injection drug users (IDUs), partly due to lack of knowledge about injection initiation.

Drug use, especially use of methamphetamines, has increased rapidly in recently years in Thailand, particularly among young people [21-23]. Sattah and colleagues [23] reported among adolescent students in northern Thailand, $41.3 \%$ males and $19.0 \%$ females ever used methamphetamines. The risk of HIV infection is high among drug users in Thailand. The reported HIV incidence was about 3\% 19\% $[22,24,25]$. As shown in other places, IDUs had a much higher risk of HIV infection than non-IDUs in northern Thailand [24-26]. Srirak et al. [21] reported that among female drug users in northern Thailand the HIV prevalence among IDUs was six more times than that among non-IDUs ( $25 \%$ vs. $4.1 \%)$. While it is feasible to deliver harm reduction programs in Thailand $[27]$, they are currently very limited $[26,28,29]$

The purpose of this study was to identify demographic and drug use factors related to onset of injection among drug users, who were admitted to one large drug treatment center, in order to provide information to develop harm reduction strategies with the hope of preventing and controlling drug injection as well as HIV infection.

\section{Methods \\ Study population}

This study was a part of a cohort study, the Opiate Users Research (OUR) Study, which was initiated at the Northern Drug Treatment Center (NDTC), located in Mae Rim, Chiang Mai Province, Thailand in 1999. NDTC is the largest drug treatment center in northern Thailand. Between February 1, 1999 and January 31, 2000 2,845 individuals were admitted for inpatient treatment, which consisted of 21-day detoxification. OUR Study inclusion criteria were: being 12 years or older; being admitted for opiate or methamphetamine dependence; agreeing to receive preand post-test HIV counseling and venipuncture for antibody testing for HIV infection; providing informed consent for those 18 and older and parental consent and assent for individuals below the age of 18 ; and completion of a behavioral questionnaire. Of 2,149 persons determined to be eligible, $1,865(87 \%)$ enrolled in this study. An additional 366 IDUs admitted to NDTC between February and December 2000 were also enrolled in the study. A total of 2,231 drug users were therefore included into this analysis. The study was approved by the institutional review boards of the Royal Thai Ministry of Public Health, Research Institute of Health Sciences, Chiang Mai University and the Johns Hopkins University.

\section{Data collection}

The study questionnaire was developed based on information from pilot studies (in-depth interviews and focus groups) and a systematic literature review. A formal pretest was conducted in a similar setting. The questionnaire has been translated into local languages and back-translated into English without information loss. Interviewers received formal training and were fluent in 12 local languages. Study participants completed the interview in their preferred language.

After explaining study requirements and obtaining informed consent, an interviewer conducted a 30-40 minute risk factor questionnaire in a private setting. Following HIV pre-test counseling, a serum specimen was collected; one week later patients were given their HIV test 
Table I: Demographic factors, sexual behaviors and drug use characteristics of 2,23 I drug users admitted to NDTC, Chiang Mai, Thailand

\begin{tabular}{|c|c|}
\hline & Number $(\%)(n=2231)$ \\
\hline Age (years), Median (IQR) & $29.3(21.4 \sim 38.5)$ \\
\hline Male & 2005 (89.9) \\
\hline Thai ethnicity & $1238(55.5)$ \\
\hline Single* & $130 \mid(58.3)$ \\
\hline Rural residence & $1685(75.5)$ \\
\hline \multicolumn{2}{|l|}{ Education } \\
\hline No schooling & $725(32.5)$ \\
\hline$\leq 6$ years & $500(22.4)$ \\
\hline 7 11 years & $635(28.5)$ \\
\hline 12 or More years & $371(16.6)$ \\
\hline Employed & $1824(81.8)$ \\
\hline Ever smoking & $2074(93.0)$ \\
\hline Ever drinking & $1805(80.9)$ \\
\hline Ever been in jail/prison & $732(32.8)$ \\
\hline HIV positive & $347(15.6)$ \\
\hline Number of sex partners, median (IQR) & $5.0(1.0 \sim 10.0)$ \\
\hline Ever selling sex & $40(1.8)$ \\
\hline Ever sex abused & $31(1.4)$ \\
\hline \multicolumn{2}{|l|}{ The first drug ever used } \\
\hline Opium & $755(33.8)$ \\
\hline Heroin & $326(14.6)$ \\
\hline Amphetamine & $478(21.4)$ \\
\hline Marijuana & $54 \mid(24.3)$ \\
\hline $\begin{array}{l}\text { Others** } \\
\text { ** }\end{array}$ & $13 \mid(5.9)$ \\
\hline $\begin{array}{l}\text { Age of drug initiation (years), median } \\
\text { (IQR) }\end{array}$ & $17.3(15.1 \sim 22.7)$ \\
\hline Ever injection & $879(39.4)$ \\
\hline
\end{tabular}

* Single includes single, separated, divorced, and widow

** Others include inhalants and tranquilizers/sedatives

results during HIV post-test counseling. The questionnaire ascertained information on demographics, tobacco and alcohol use, non-parenteral modes of HIV transmission, and a comprehensive drug use and sexual behavior history. Drug use history included lifetime use of marijuana, opium, heroin, methamphetamines, inhalants (paint thinner and glue), sedatives and hypnotics, and other drugs. Age at first use, priority of reasons for first use, and use in the past year and in the past three months were assessed for each drug. Route of drug administration (inhalation, ingestion, and injection), frequency of use, amount taken per dose, and purchase price of each drug were assessed for all drugs used in the past 3 months. Injection history was also obtained, including characteristics of first injection, syringe sharing history, and syringe disinfection practices. Drug treatment and family and friends' drug use were also examined.

\section{Dependent and independent variables}

Independent variables included demographic factors, sexual behaviors and drug use characteristics, specifically age, gender, ethnicity, education, employment, residence, number of sex partner, sex abuse history, types of drugs ever used, and age of drug initiation. The dependent variable was initiation of injection.

\section{Statistical methods}

Univariate analysis was conducted to describe the study sample's demographics, sex and drug use behaviors. Continuous variables (age, number of lifetime sex partners and age of drug initiation) were roughly categorized based on their quartiles in the statistical analyses. Logistic regression was employed to assess both unadjusted and independent effects of potential risk factors. Variables that were included in the initial and final multiple logistic models were based on statistical significance $(p<0.05)$ and/or scientific importance. Interaction terms were systematically tested. A manual back-and-forth process was employed to obtain the final parsimonious model. SAS software (version 9.1, SAS Institute, Cary, North Carolina) was used to conduct the analysis.

\section{Results \\ Demographic factors, sexual behaviors and drug use characteristics}

Descriptive results are located in Table 1. The median age of this sample was 29.3 years with an inter-quartile range (IQR) of $21.4 \sim 38.5$ years. Nearly $90 \%$ of participants were male and more than half $(55.5 \%)$ were Thai, with the remaining being ethnic minorities. In this analysis, the marital statue of single (58.5\%) included those who were single, separated, divorced or widowed. Two-thirds of the sample lived in rural areas. About one-third had no formal education and only $16.6 \%$ completed 12 or more years of education. Most of the participants were employed (81.8\%). Both smoking $(93.0 \%)$ and drinking $(80.9 \%)$ were very common. About one-third of participants ever gave a history of incarceration. The HIV prevalence of this sample was $15.6 \%$.

Half of the participants had five or more lifetime sex partners with an IQR of $1 \sim 10$. Forty participants $(1.8 \%)$ ever sold sex for money or drug and thirty one $(1.4 \%)$ reported they were sexually abused.

Opium (33.8\%) was the most common initiation drug, followed by marijuana (24.3\%), amphetamine (21.4\%) and heroin $(14.6 \%)$. The median age of drug initiation was 17.3 years with an IQR of $15.1 \sim 22.7$ years. In total, 879 participants (39.4\%) ever injected drugs.

\section{Correlates of injection initiation}

Table 2 shows results from bivariate analysis. The unadjusted odds ratio [UOR] indicated that older age (20 years of age or over), male, Thai ethnicity and single civil status were associated with a higher risk of injection initiation. Drug users living in rural areas had less likelihood to ini- 
tiate injection than those living in urban areas (UOR = 0.39). Comparing to those with no formal schooling, any formal education increased the likelihood of injection initiation. A history of smoking, drinking or incarceration related to higher risk of injection initiation. Multiple sex partners and a history of selling sex or reporting sex abuse were associated with increased likelihood of injection initiation. Comparing to opium users, using marijuana, heroin or other drugs had a higher risk of injection initiation while using amphetamine as the initiation drug was associated with a much lower risk. Comparing to drug users at younger age (less than 16 years old), those at 16 to 18 years of age had a higher risk of injection initiation, while those at 24 years of age or older had a lower risk.

Table 3 contains results from multiple logistic models examining demographic, sexual, and drug use characteristics associated with injection initiation. In the presence of other variables, the demographics that were found significantly associated with initiation of injection were: being 20 years or older (Adjusted Odds Ratio $[\mathrm{AOR}]=4.3$ for those 20 29 years old; AOR $=6.0$ for those 30 39 years old; and $\mathrm{AOR}=5.3$ for those 40 years of age or older); being single, $(\mathrm{AOR}=1.7)$; and being urban (change the direction of the AOR). Those who had more education (compared to those without schooling, AOR $=1.7$ for those with 6 or less years of education; $\mathrm{AOR}=1.8$ for those with 7 11 years of eduction; and AOR $=12$ or more years of education), ever smoking $(\mathrm{AOR}=2.9)$ or being incarcerated (AOR $=5.0)$ all had an increased risk of starting injection.

In terms of sex behaviors, more sex partners implied higher risk of transition into injection (comparing to those who did not have any or only one sex partner, AOR $=1.5$ for those with $6 \sim 10$ partners; and AOR $=1.9$ for those with 11 or more partners). Having a history of sex abuse was significantly associated with heightened risk of starting injection $(\mathrm{AOR}=3.3)$.

In terms of drug use, the type of initiation drug mattered: comparing to opium users, heroin use was related to higher likelihood of transition into injection ( $\mathrm{AOR}=2.7$ ), while amphetamine use was associated with a lower risk of injection initiation (AOR $=0.098$ ). Age of drug initiation had a significant impact on the likelihood of starting injection: compared to those who began drug use at less than 16 years, the risk of initiating drug use at the age of 19 23 years old was about half $(\mathrm{AOR}=0.56)$ as likely and about one-quarter as likely ( $\mathrm{AOR}=0.25$ ) for those initiating drug use at the age of 24 years or older.

\section{Discussion}

The study's findings indicate that demographic factors, sexual behaviors and drug use characteristics account for some of the risks in transition into injection. Drug users who were older or single, obtained more education, lived in urban areas, ever smoked or had an experience of incarceration were more likely to initiate injection. Multiple sex partners or a history of sex abuse related to a higher likelihood of starting injection; using amphetamines instead of heroin as the starting substance of abuse and later drug initiation were associated with a lower risk of injection initiation.

Contrary to a study conducted among street youths (1425 years of age) in Montreal, Canada [5], our data showed that older age was associated with a higher risk of initiation into injection. The obvious difference in study settings and age structure between the two studies may account for some of the difference in the age effects. Our study participants were from a resource-limited country and older than those in the Canada study. Furthermore, all our participants were drug users, whose age was apparently associated with both drug use history and mode of drug administration. Old drug users might have involved in the drug culture for an extended period of time. Thus, it is not surprising that older drug users had great opportunity to transition into injection. In this analysis the effect of drug use history was partly controlled by including age of drug initiation into the final model; however, the impact of initial and sequential drug use modes on transition into injection was not extensively explored.

As a contextual factor, neighborhood (residence) has been shown as an importance determinant of starting injection [30]. Since most studies have been conducted in developed countries, the effect of rural residence on initiation of injection is unknown. Our data demonstrated that people living in rural areas had half the risk to initiate injection as those in urban areas after controlling for other confounders such as education. Ethnicity and employment were initially included into the model but were dropped due to statistical non-significance. In current analysis, postal code was employed to define the types of residence, and current residence was used as a surrogate for the neighborhood that influenced the occurrence of injection, which may have been inaccurate. If more detailed information is available, it would be helpful to explore how contextual factors influence and shape drug users' behavior and injection practices in Thailand. As Galea et al. [31] point out, to fully understand drug use behaviors, researchers should address not only individual risk behaviors but also contextual factors such as social norms and neighborhood socioeconomic status by means of statistical methods like multilevel analysis.

Not reported from some studies [5,32], we found multiple sex partners ( 6 or more) to be a risk factor of transition into injection. However, in line with other studies $[5,13]$, 
Table 2: Unadjusted odds ratio for factors associated with initiation of injection

\begin{tabular}{|c|c|}
\hline & Unadjusted odds ratio $(95 \% \mathrm{Cl})$ \\
\hline \multicolumn{2}{|l|}{ Age } \\
\hline Under 20 years old & Reference \\
\hline 20 29 years old & $8.3(6.0 \sim 11.4)$ \\
\hline $30 \sim 39$ years old & $6.6(4.8 \sim 9.2)$ \\
\hline 40 years old or older & $3.2(2.3 \sim 4.5)$ \\
\hline Male & $2.2(1.6 \sim 3.1)$ \\
\hline Thai ethnicity & $1.4(1.2 \sim 1.7)$ \\
\hline Single & $1.6(1.3 \sim 1.9)$ \\
\hline Rural residence & $0.39(0.32 \sim 0.47)$ \\
\hline \multicolumn{2}{|l|}{ Education } \\
\hline No schooling & Reference \\
\hline$\leq 6$ years & $2.5(1.9 \sim 3.1)$ \\
\hline 7 11 years & $1.4(1.1 \sim 1.8)$ \\
\hline 12 or more years & $2.5(1.9 \sim 3.2)$ \\
\hline Employed & $0.96(0.77 \sim 1.2)$ \\
\hline Ever smoking & $7.3(4.2 \sim 12.7)$ \\
\hline Ever drinking & $2.1(1.6 \sim 2.6)$ \\
\hline Ever in jail & $7.2(5.9 \sim 8.7)$ \\
\hline \multicolumn{2}{|l|}{ No. of lifetime sex partners } \\
\hline One or no partner & Reference \\
\hline 2 5 partners & $2.4(1.9 \sim 3.1)$ \\
\hline $6 \sim 10$ partners & $3.9(2.9 \sim 5.2)$ \\
\hline II or more partners & 6.1 (4.7 7.9) \\
\hline Ever selling sex & $2.9(1.5 \sim 5.6)$ \\
\hline Ever sex abused & $2.8(1.4 \sim 6.0)$ \\
\hline \multicolumn{2}{|l|}{ Type of initiation drug } \\
\hline Opium & Reference \\
\hline Marijuana & $3.4(2.7 \sim 4.2)$ \\
\hline Heroin & $3.4(2.6 \sim 4.5)$ \\
\hline Amphetamine & $0.13(0.085 \sim 0.20)$ \\
\hline Others & $3.9(2.6 \sim 5.7)$ \\
\hline \multicolumn{2}{|l|}{ Age of drug initiation } \\
\hline Under 16 years old & Reference \\
\hline $16 \sim 18$ years old & $1.5(1.2 \sim 1.8)$ \\
\hline 19 23 years old & $1.0(0.80 \sim 1.3)$ \\
\hline 24 years old or older & $0.39(0.30 \sim 0.50)$ \\
\hline
\end{tabular}

the experience of sexual abuse increased the likelihood of injection initiation. Though not explored in this study, others $[33,34]$ have demonstrated that negative life events and risky behaviors following sex abuse could be possible mechanisms in the casual chain. In our study we cannot determine the temporal relationships between sex behaviors and injection initiation, which makes it hard to establish the causal pathway.

Comparing to opium, taking heroin as the initiation drug was associated with a larger likelihood of transition into injection, while starting with amphetamines lowered the risk. Mode of drug administration and multiple drug use following initiation drug might account for their specific effect. In the past three months, $72.9 \%$ of heroin users injected the drug, while only $7.5 \%$ of amphetamine users were injectors (data not shown). Furthermore, those start- ing with amphetamines tended to stick with it; only $12.3 \%$ of them ever used heroin. Though behaviors in the past three months were not necessarily constant over time, they at least indicated some drug use pattern in our sample. Among individuals starting from marijuana or others (inhalants and tranquilizers/sedatives), 59.7\% and $54.2 \%$ ever tried opium sometime late respectively, which might partly explain the non-significant difference in risk of injection between marijuana or others with opium. Multiple drug use and the intensity of drug use were not examined in the current analysis, though many other studies $[10,11,14]$ have indicted that they are related to a higher risk of initiating injection.

In our study, younger age of drug initiation was significantly associated with a higher risk of injection initiation even after controlling for the effect of age and other demographics, which has not been reported in other studies [5,32]. The interaction between age and age of drug initiation was examined and the effect was not statistically significant. As indicated by our results, those starting drug use at less than 16 years had four times the risk of transition into injection than those starting at the age 24 years or older. One implication for this finding is to focus health education programs on youths.

The HIV prevalence at study enrollment among drug users in our sample was $15.6 \%$, which was comparable to the results from other studies in similar settings $[22,24,25]$. Compared to the estimated HIV prevalence of $1 \sim 2 \%$ among the adult population in Thailand [35], the risk of HIV infection among drug users was clearly quite high. Further analyses (data not shown) indicated that the risk of HIV infection varied by age, age at drug initiation, injection status and types of recently used drugs. Drug users 20 years old or over had a higher prevalence of HIV infection than those younger than 20 years old $(18.4 \%$ vs. $3.7 \%$, P $<0.0001$ ), while those starting drugs at younger age (under 16 years old) had a higher risk of HIV infection than those starting drug use at older ages (age of 16 years old or over) $(17.9 \%$ vs. $7.3 \%, \mathrm{P}<0.0001)$. Considering the correlations between age, length of drug use (age of drug initiation), and the accumulated risk of HIV infection during the entire course of drug use, the observed differences in the risk of HIV infection between different age groups and length of drug use were reasonable but unacceptable. HIV prevention programs and health education projects need to be enhanced and should target the population at risk, especially youth. The HIV prevalence among IDUs was $35.2 \%$ in our sample, which was 12.6 times higher than that of non-IDUs $(2.8 \%)(\mathrm{P}<0.0001)$. In terms of drug use in the past 3 months, HIV prevalence was highest among users of other drugs (inhalants and tranquilizers/sedatives, $35.1 \%$ ), followed by heroin users $(29.9 \%)$, amphetamine users $(16.0 \%)$, marijuana users 
Table 3: Adjusted odds ratio for factors associated with initiation of injection

\begin{tabular}{|c|c|}
\hline & Adjusted odds ratio $(95 \% \mathrm{Cl})$ \\
\hline \multicolumn{2}{|l|}{ Age } \\
\hline Under 20 years old & Reference \\
\hline 20 29 years old & $4.3(2.7 \sim 6.8)$ \\
\hline $30 \sim 39$ years old & $6.0(3.6 \sim 10.2)$ \\
\hline 40 years old or older & $5.3(3.0 \sim 9.3)$ \\
\hline \multicolumn{2}{|l|}{ Male } \\
\hline \multicolumn{2}{|l|}{ Thai ethnicity } \\
\hline Single & $1.7(1.3 \sim 2.2)$ \\
\hline Rural residence & $0.50(0.37 \sim 0.66)$ \\
\hline \multicolumn{2}{|l|}{ Education } \\
\hline No schooling & Reference \\
\hline$\leq 6$ years & $1.7(1.2 \sim 2.3)$ \\
\hline $7 \sim 11$ years & $1.8(1.2 \sim 2.7)$ \\
\hline 12 or more years & $1.5(1.0 \sim 2.3)$ \\
\hline \multicolumn{2}{|l|}{ Employed } \\
\hline Ever smoking & $2.9(1.5 \sim 5.3)$ \\
\hline \multicolumn{2}{|l|}{ Ever drinking } \\
\hline Ever in jail & $5.0(4.0 \sim 6.4)$ \\
\hline \multicolumn{2}{|l|}{ No. of lifetime sex partners } \\
\hline One or no partner & Reference \\
\hline 2 5 partners & I.I (0.83 1.6) \\
\hline $6 \sim 10$ partners & $1.5(1.0 \sim 2.2)$ \\
\hline II or more partners & $1.9(1.4 \sim 2.7)$ \\
\hline \multicolumn{2}{|l|}{ Ever selling sex } \\
\hline Ever sex abused & $3.3(1.2 \sim 9.1)$ \\
\hline \multicolumn{2}{|l|}{ Type of initiation drug } \\
\hline Opium & Reference \\
\hline Marijuana & $0.98(0.68 \sim 1.4)$ \\
\hline Heroin & $2.7(1.9 \sim 3.8)$ \\
\hline Amphetamine & $0.098(0.057 \sim 0.17)$ \\
\hline Others & $1.2(0.70 \sim 2.1)$ \\
\hline \multicolumn{2}{|l|}{ Age of drug initiation } \\
\hline Under 16 years old & Reference \\
\hline $16 \sim 18$ years old & $0.83(0.60 \sim 1.1)$ \\
\hline 19 23 years old & $0.56(0.39 \sim 0.79)$ \\
\hline 24 years old or older & $0.25(0.16 \sim 0.37)$ \\
\hline
\end{tabular}

(15.0\%) and opium users (10.4\%). A study from the same region [21] reported the HIV prevalence was $25 \%$ among heroin injectors and $4.1 \%$ among opium or methamphetamine smokers. Gender could be one reason to the observed difference in HIV risk since the sample for the above study only included females. However, in our sample $44.2 \%$ of participants were multi-drug users. In the past 3 months, $61.7 \%$ of inhalants and tranquilizers/sedatives users, $46.4 \%$ of marijuana users, $40.8 \%$ of amphetamine users, and $21.9 \%$ opium users also reported using heroin, which matched well with the observed HIV risk for individual drugs. As shown in elsewhere [36], multiple drug use was associated with a higher risk of HIV infection, especially when heroin injection was involved. This finding indicates the importance of addressing the issue of multiple drug use in harm reduction programs, and not just focusing on injection of heroin or methamphetamines.

The interpretation of these results is subject to certain limitations. One concern is the representativeness of the sample. Recruited from one large drug treatment center, drug users in our study could be a highly selected group with relatively high risks. Data have shown that a history of drug treatment may reflect past severity of drug dependence, itself a predictor of transition into injection $[12,14]$. Secondly, all behavioral data were from self-reports that might be inaccurate. Nevertheless, all interviewers were asked to evaluate the quality of the interview at the end of each interview and most reported good cooperation and judged the data to be moderately to very reliable. A study by McElrath and colleagues [37] also showed that retrospective self-reports from injection drug users had good reliability and consistency. The extent of under-reporting of socially unacceptable activities or over-reporting was unknown and inaccessible. Thirdly, some informative variables such as types, modes, and intensiveness of drug use prior to injection initiation were not assessed. Exploring these risk factors could shed additional understanding of the process of initiating injection, and might also benefit the design of appropriate harm reduction program to target the individuals at risk. Finally, the cross-sectional design of this study limited our ability to determine causality; some potential risk factors for transition into injection might result from the fact that the participant initiated injection and then identified those experiences a risk context, such as being in jail. Furthermore, the use of a cross-sectional design could induce recall bias and survival bias.

Despite these limitations, we have identified several correlates of injection initiation among drug users in this Southeast Asian context. Understanding the factors related to initiation into injection may be an important tool in guiding how we modify current harm reduction strategies or design new approaches to more specifically target high-risk populations and high-risk behaviors to delay or prevent the initiation of injection.

\section{Conclusion}

Injection initiation was related to several demographic factors, sexual behaviors and drug use characteristics in northern Thailand. The information from this study could be employed to improve current efforts in harm reduction in order to better serve the people at risk.

\section{Competing interests}

The author(s) declare that they have no competing interests. 


\section{Authors' contributions}

DDC, VS and JJ conceived of the study and directed study operations; NS, TV and MHR were instrumental in the conduct of the field operations, and participated in interpretation of the data. YC, SGS, SK and TS conducted the statistical analysis. DDC drafted the manuscript; all authors read and approved the final manuscript.

\section{Acknowledgements}

This research was funded by the National Institute of Drug Abuse ( $\mathrm{R}$ OI DA I I 33), the Fogarty International Center (DW43-0000I) and the Royal Thai Government. The authors are grateful to Wendy W. Davis for valuable comments on an earlier draft of the paper.

\section{References}

I. Swift W, Maher L, Sunjic S: Transitions between routes of heroin administration: a study of Caucasian and Indochinese heroin users in south-western Sydney, Australia. Addiction 1999, 94:7I-82.

2. Neaigus A, Miller M, Friedman SR, Hagen DL, Sifaneck SJ, Ildefonso G, des Jarlais DC: Potential risk factors for the transition to injecting among non-injecting heroin users: a comparison of former injectors and never injectors. Addiction 2001, 96:847-60.

3. Fuller CM, Vlahov D, Ompad DC, Shah N, Arria A, Strathdee SA: High-risk behaviors associated with transition from illicit non-injection to injection drug use among adolescent and young adult drug users: a case-control study. Drug and Alcohol Dependence 2002, 66:189-98.

4. Bravo MJ, Barrio G, de la Fuente L, Royuela L, Domingo L, Silva T: Reasons for selecting an initial route of heroin administration and for subsequent transitions during a severe HIV epidemic. Addiction 2003, 98:749-60.

5. Roy E, Haley N, Leclerc P, Cedras L, Blais L, Boivin JF: Drug injection among street youths in Montreal: predictors of initiation. Journal of Urban Health 2003, 80:92-105.

6. Carneiro M, Fuller C, Doherty MC, Vlahov D: HIV prevalence and risk behaviors among new initiates into injection drug use over the age of $\mathbf{4 0}$ years old. Drug and Alcohol Dependence 1999, 54:83-86.

7. Doherty MC, Garfein RS, Monterroso E, Brown D, Vlahov D: Correlates of HIV infection among young adult short-term injection drug users. AIDS 2000, 14:717-26.

8. Kral AH, Lorvick J, Edlin BR: Sex- and drug-related risk among populations of younger and older injection drug users in adjacent neighborhoods in San Francisco. J Acquir Immune Defic Syndr 2000, 24:162-167.

9. van Ameijden EJ, Coutinho RA: Large decline in injecting drug use in Amsterdam, 1986-1 998: explanatory mechanisms and determinants of injecting transitions. Journal of Epidemiology and Community Health 200I, 55:356-63.

10. Darke S, Swift W, Hall W, Ross M: Predictors of injecting and injecting risk-taking behaviour among methadone-maintenance clients. Addiction 1994, 89:3 I I-6.

II. Irwin KL, Edlin BR, Faruque S, McCoy HV, Word C, Serrano Y, Inciardi J, Bowser B, Holmberg SD, The Multicenter Crack Cocaine and HIV Infection Study Team: Crack cocaine smokers who turn to drug injection: characteristics, factors associated with injection, and implications for HIV transmission. Drug and Alcohol Dependence 1996, 42:85-92.

12. van Ameijden EJ, van den Hoek JA, Hartgers C, Coutinho RA: Risk factors for the transition from noninjection to injection drug use and accompanying AIDS risk behavior in a cohort of drug users. American Journal of Epidemiology 1994, 139: I 153-63.

13. Ompad DC, Ikeda RM, Shah N, Fuller CM, Bailey S, Morse E, Kerndt P, Maslow C, Wu Y, Vlahov D, Garfein R, Strathdee SA: Childhood sexual abuse and age at initiation of injection drug use. Am J Public Health 2005, 95:703-9.

14. Des Jarlais DC, Casriel C, Friedman SR, Rosenblum A: AIDS and the transition to illicit drug injection--results of a randomized trial prevention program. British Journal of Addiction 1992, 87:493-8.
15. Ross J, Darke S, Hall W: Transitions between routes of benzodiazepine administration among heroin users in Sydney. Addiction 1997, 92:697-705.

16. Chamla D, Chamla JH, Dabin W, Delin H, Rennes N: Transition to injection and sharing of needles/syringes: Potential for HIV transmission among heroin users in Chengdu, China. Addict Behav in press. 2005 Jun 24

17. Lai S, Chen J, Celentano D, Page JB, Lai H, Yang J, Liu W, McCoy CB, Yu XF: Adoption of injection practices in heroin users in Guangxi Province, China. J Psychoactive Drugs 2000, 32:285-92.

18. Novelli LA, Sherman SG, Havens JR, Strathdee SA, Sapun M: Circumstances surrounding the first injection experience and their association with future syringe sharing behaviors in young urban injection drug users. Drug Alcohol Depend 2005, 77:303-9.

19. Punpanich W, Ungchusak K, Detels R: Thailand's Response to the HIV Epidemic: Yesterday, Today, and Tomorrow. AIDS Education and Prevention 2004:119-136.

20. UNAIDS/WHO>: AIDS epidemic update: December 2003 Geneva: UNAIDS/WHO; 2003.

21. Srirak N, Kawichai S, Vongchak T, Razak MH, Jittiwuttikarn J, Tovanabutra S, Rungruengthanakit K, Keawvichit R, Beyrer C, Wiboonatakul K, Sripaipan T, Suriyanon V, Celentano DD: HIV infection among female drug users in Northern Thailand. Drug Alcohol Depend 2005, 78: I4I-5.

22. Beyrer C, Razak MH, Jittiwutikarn J, Suriyanon V, Vongchak T, Srirak N, Kawichai S, Tovanabutra S, Rungruengthanakit K, Sawanpanyalert P, Sripaipan T, Celentano DD: Methamphetamine users in northern Thailand: changing demographics and risks for HIV and STD among treatment-seeking substance abusers. Int J STD AIDS 2004, I 5:697-704.

23. Sattah MV, Supawitkul S, Dondero T], Kilmarx PH, Young NL, Mastro TD, Chaikummao S, Manopaiboon C, Griensven F: Prevalence of and risk factors for methamphetamine use in northern Thai youth: results of an audio-computer-assisted self-interviewing survey with urine testing. Addiction 2002, 97:80I-8.

24. Sawanpanyalert P, Supawitkul S, Yanai H, Saksoong P, Piyaworawong $S$ : Trend of HIV incidence rates among drug users in an HIV epicenter in northern Thailand (1989-1997). J Epidemiol 1999 , 9:1 I 4-20.

25. Celentano DD, Hodge MJ, Razak MH, Beyrer C, Kawichai S, Cegielski JP, Nelson KE, Jittiwutikarn J: HIV-I incidence among opiate users in northern Thailand. Am J Epidemiol 1999, 149:558-64.

26. Razak MH, Jittiwutikarn J, Suriyanon V, Vongchak T, Srirak N, Beyrer C, Kawichai S, Tovanabutra S, Rungruengthanakit K, Sawanpanyalert $P$, Celentano DD: HIV prevalence and risks among injection and noninjection drug users in northern Thailand: need for comprehensive HIV prevention programs. I Acquir Immune Defic Syndr 2003, 33:259-66.

27. Gray J: Harm reduction in the hills of northern Thailand. Subst Use Misuse 1998, 33:1075-91.

28. Beyrer C, Jittiwutikarn J, Teokul W, Razak MH, Suriyanon V, Srirak N, Vongchuk T, Tovanabutra S, Sripaipan T, Celentano DD: Drug use, increasing incarceration rates, and prison-associated HIV risks in Thailand. AIDS Behav 2003, 7:153-6I.

29. Kawichai S, Celentano DD, Vongchak T, Beyrer C, Suriyanon V, Razak MH, Srirak N, Rungruengthanakit K, Jittiwutikarn J: HIV Voluntary Counseling and Testing and HIV Incidence in Male Injecting Drug Users in Northern Thailand: Evidence of an Urgent Need for HIV Prevention. J Acquir Immune Defic Syndr 2006, 4I:186-193.

30. Fuller CM, Borrell LN, Latkin CA, Galea S, Ompad DC, Strathdee SA, Vlahov D: Effects of race, neighborhood, and social network on age at initiation of injection drug use. Am J Public Health 2005, 95:689-95.

31. Galea S, Ahern J, Vlahov D: Contextual determinants of drug use risk behavior: a theoretic framework. J Urban Health 2003:iii50-8.

32. Fuller CM, Vlahov D, Arria AM, Ompad DC, Garfein R, Strathdee SA: Factors associated with adolescent initiation of injection drug use. Public Health Rep 200I:I36-45.

33. Molnar BE, Buka SL, Kessler RC: Child sexual abuse and subsequent sychopathology: results from the National Comorbidity Survey. Am J Public Health 200I, 91 : 753-760.

34. Swanston HY, Plunkett AM, O'Toole BI, Shrimpton S, Parkinson PN, Oates RK: Nine years after child sexual abuse. Child Abuse Negl 2003, 27:967-984. 
35. Monitoring the AIDS Pandemic (MAP): The status and trends of HIVI AIDS/STI epidemics in Asia and the Pacific Provisional report Melbourne, Australia; 2001.

36. Greenwood GL, White EW, Page-Shafer K, Bein E, Osmond DH, Paul J, Stall RD: Correlates of heavy substance use among young gay and bisexual men: The San Francisco Young Men's Health Study. Drug Alcohol Depend 200I, 61:105-12.

37. McElrath K, Chitwood DD, Griffin DK, Comerford M: The consistency of self-reported HIV risk behavior among injection drug users. American Journal of Public Health 1994, 84: I 965-70.

Publish with Bio Med Central and every scientist can read your work free of charge

"BioMed Central will be the most significant development for disseminating the results of biomedical research in our lifetime. " Sir Paul Nurse, Cancer Research UK

Your research papers will be:

- available free of charge to the entire biomedical community

- peer reviewed and published immediately upon acceptance

- cited in PubMed and archived on PubMed Central

- yours - you keep the copyright

Submit your manuscript here:

http://www.biomedcentral.com/info/publishing_adv.asp 